\title{
cheer
}

\section{Sistema Nacional de Atendimento Socioeducativo como mecanismo de regulamentação da punição}

\section{Roberto Bassan Peixoto}

Superintendente do Sistema Estadual de Atendimento Socioeducativo Governo do Estado do Ceará

robertobpeixoto@uol.com.br

ORCID: 0000-0002-5554-7842

\section{Resumo}

\begin{abstract}
Este artigo apresenta uma reflexão sobre o fundamento e práticas no contexto do Sistema Nacional de Atendimento Socioeducativo (Sinase), que demonstra como as ações no cotidiano dos centros socioeducativos refletem o controle social, regulamentando um processo de punição, incluindo óbitos de jovens durante o cumprimento da medida socioeducativa de internação, reafirmando uma cultura punitiva das unidades de internação para adolescentes como instituições totais. A segunda parte do texto analisa a intencionalidade oculta da privação de liberdade de adolescentes: o mito da socioeducação, no qual, mesmo com iniciativas pedagógicas e ações de formação, as práticas reforçam uma lógica sistêmica voltada aos interesses do capital, reforçando a estigmatização dos jovens e a segregação social.
\end{abstract}

Palavras-chave medidas socieoducativas, centros de socioeducação, políticas públicas, privação de liberdade, adolescentes. 


\title{
Brazilian National System of Socio-Educational Services as a punishment regulation mechanism
}

\begin{abstract}
This article presents a reflection on the rationale and practices in the context of the Brazilian National System of Socio-Educational Services (Sistema Nacional de Atendimento Socioeducativo [SINASE]), which demonstrates how daily actions in socio-educational centers reflect social control, regulating a punishment process, including youth deaths while serving as inmates in socio-educational facilities, reaffirming a punitive culture of youth detention facilities as total institutions. The second part of the text analyzes the hidden intentionality of youth deprivation of liberty: the myth of socio-education, in which, even with pedagogical initiatives and educational actions, the practices reinforce a systemic logic focused on the interests of capital, reinforcing youth stigmatization and social segregation.
\end{abstract}

Key words socio-educational measures, socio-education centers, public policy, deprivation of liberty, adolescents.

\section{Sistema Nacional Brasileño de Servicios Socioeducativos como mecanismo de regulación del castigo}

\section{Resumen}

Este artículo presenta una reflexión sobre los fundamentos y las prácticas en el contexto del Sistema Nacional Brasileño de Servicios Socioeducativos (Sistema Nacional de Atendimento Socioeducativo [SINASE]), que demuestra cómo las acciones cotidianas en los centros socioeducativos reflejan el control social, regulando un proceso de castigo, incluyendo muertes de jóvenes durante el cumplimiento de la medida socioeducativa en una institución, reafirmando una cultura punitiva de los centros de detención para adolescentes como instituciones totales. La segunda parte del texto analiza la intencionalidad oculta de la privación de libertad de adolescentes: el mito de la socioeducación, en el que, incluso con iniciativas pedagógicas y acciones formativas, las prácticas refuerzan una lógica sistémica centrada en los intereses del capital, reforzando la estigmatización de jóvenes y la segregación social.

Palabras clave medidas socioeducativas, centros socioeducativos, políticas públicas, privación de libertad, adolescentes.

\section{Système National Brésilien de Services Socio-Educatifs comme mécanisme de régulation des peines}

\section{Résumé}

Cet article présente une réflexion sur le fondement et les pratiques dans le contexte du Système National Brésilien de Services Socio-Educatifs (Sistema Nacional de Atendimento Socioeducativo [SINASE]), qui montre comment les actions quotidiennes des centres socio-éducatifs reflètent le contrôle social, régulant un processus de punition, y compris la mort de jeunes alors qu'ils étaient détenus dans des établissements socio-éducatifs, réaffirmant une culture punitive des unités de détention pour adolescents en tant qu'institutions totales. La deuxième partie du texte analyse l'intentionnalité cachée de la privation de liberté des adolescents: le mythe de la socio-éducation, dans lequel, même avec des initiatives pédagogiques et des actions de formation, les pratiques renforcent une logique systémique centrée sur les intérêts du capital, renforçant la stigmatisation des jeunes et la ségrégation sociale.

Mots-clés mesures socio-éducatives, centres socio-éducatifs, politiques publiques, privation de liberté, adolescents. 


\section{Cultura punitiva em ação: as unidades de internação para adolescentes como instituições totais}

Pode-se afirmar que as unidades de internação para adolescentes em conflito com a lei, para execução de medidas socioeducativas, estão inscritas em uma lógica de controle social e submissão. Por mais que todas não funcionem da mesma maneira e que existam alguns modelos isolados de boas práticas - principalmente em decorrência de esforços de profissionais engajados e preocupados em garantir os direitos humanos - todas as unidades ficam à mercê do sistema e cumprem as regras estabelecidas como instrumentos da cultura punitiva:

[...] cumpre uma função de legitimação cada vez mais necessária à perpetuação da "ordem social" uma vez que a evolução das relações de força entre as classes tende a excluir de modo mais completo a imposição de uma hierarquia fundada na afirmação bruta e brutal das relações de força (Bourdieu, 1989, p. 311).

A experiência profissional de quase 2 décadas no sistema de atendimento socioeducativo brasileiro indica que as estruturas e práticas existentes nessas instituições não refletem ignorância, acaso ou o mero discurso de herança de outros tempos perversos. Estamos diante de recursos, práticas e projetos, geridos e moldados com objetivos concretos, a serviço de uma lógica punitiva voltada às classes menos favorecidas. Ainda que encontremos nessas unidades esforços e práticas que envolvem atividades educacionais, recreativas e esportivas, elas se caracterizam como instituições totais, forjadas para o doutrinamento e a submissão do indivíduo:

A tendência absorvente ou totalizadora está simbolizada pelos obstáculos que se opõe frente à interação social com o exterior e ao êxodo dos membros, e que só adquirem forma material: portas cerradas, altos muros, arames farpados (Goffman, 2008, p. 144).

Em suma, estamos diante de jovens que passam de 16 a 20 horas por dia em seus alojamentos, trancados - a média de atividades diárias para os adolescentes em cumprimento de medida socioeducativa de internação no Brasil é bem inferior a 8 horas diárias, na maioria das unidades não se chega a 4 horas diárias. Isso considerando, ainda, ações de segurança e deslocamentos dos jovens dentro dessas unidades; eles passam a 
maior parte do tempo reclusos em seus "alojamentos", termo usado para se referir com humanidade às celas trancadas, com grades, ferrolhos e cadeados. Nesse tempo de reclusão, a vida dos jovens, seu mundo, limita-se à relação com outros jovens privados de liberdade e com agentes socioeducativos, que preferem manter distância, exercendo o papel de carcereiros. Todos os horários, levantar, comer, tomar banho, tudo se pauta por e gira ao redor de normativas de "segurança" na unidade:

\footnotetext{
Todos os aspectos da vida se desenvolvem no mesmo lugar e frente à mesma autoridade única. Segundo, cada etapa de atividade diária de um membro está sempre em companhia imediata de um grande número de outros, a quem se dá o mesmo tratamento e [requer-se] que façam juntos as mesmas coisas. Terceiro, todas as etapas das atividades se impõem desde cima, mediante um sistema de normas formais explícitas e um corpo de funcionários (Goffman, 2008, p. 145).
}

Essa parece ser uma descrição fidedigna dos atuais centros de socioeducação no Brasil, instituições totais que ainda assumem um discurso de defesa de tais ações em nome de uma pseudossegurança. Sempre há uma normativa interna que regulamenta essas ações de segurança. E quem exerce o papel de educador social, o agente socioeducativo, prefere a figura do agente de segurança e mantém distância na relação humana/educativa do sujeito que se encontra privado de liberdade. Suas funções passam a ser controlar, saber onde cada um deve estar e em que momento isso ocorre, tendo como único objetivo a manutenção da ordem estabelecida.

\footnotetext{
No grande ponoptismo social cuja função é precisamente a transformação da vida dos homens em força produtiva, a prisão exerce uma função muito mais simbólica e exemplar do que realmente econômica, penal ou corretiva. A prisão é a imagem da sociedade e a imagem invertida da sociedade, imagem transformada em ameaça (Foucault, 1997, p. 123).
}

As práticas dessas unidades, a partir de uma estrutura carcerária, convertem a medida socioeducativa de internação em um espaço "necessário" para a manutenção da ordem dentro do sistema repressivo e inumano. Decerto existem situações de violência entre os próprios internos, em algumas ocasiões a garantia de direitos de uns passa pela limitação de direitos de outros. Mas o problema não é essa limitação, senão a anulação total de direitos, a perversão de um sistema, dificilmente apreciado por quem o dirige e controla esse cárcere, acaba convertendo-o em um processo de resolução de conflitos do 
tipo perde-perde: a) os internos se angustiam, animalizam, enlouquecem e até morrem; b) os funcionários suportam as agressividades e, com frequência, recorrem à violência, carecendo do equilíbrio necessário para respeitar o sujeito preso; c) o próprio sistema se converte em algo ilegítimo; e d) os cidadãos entendem que o custo econômico do cárcere serve a fins racionais revestidos de constitucionalidade formal.

Nessa lógica, a maioria dos centros de socioeducação adota um ideário meritocrático: se o interno se comportar bem diante dos educadores e obedecer às normas, terá mais privilégios de saída, mais atividades. Esse modus operandi assume ainda mais peso quando os jovens atingem a maioridade (18 anos): se têm apresentado bom comportamento e mostram-se obedientes, há possibilidade de envio de relatórios favoráveis à sua desinternação.

No sentido contrário, os adolescentes em situação de desvantagem apresentam mais fatores de risco em suas famílias e seu entorno e características infantis, que influenciam seu comportamento na unidade, não obtendo determinados privilégios devido ao seu comportamento mais rebelde - por vezes, permanecem privados de liberdade depois de completarem 18 anos. Este é um paradoxo do sistema: o mais desamparado é quem mais se desampara nas unidades, tendo em vista que incomoda, desafia, "dá trabalho". Na realidade, o objetivo da instituição deveria ser proporcionar o suporte necessário aos mais desamparados:

\begin{abstract}
A ideologia da pena era a do treinamento, mediante controle estrito da conduta do apenado, sem que este pudesse dispor de um só instante de privacidade. Essa ideologia será expandida e formulada pelos diversos criadores de regimes e sistemas "progressivos", mas no fundo seguirá sendo a mesma: vigilância, arrependimento, aprendizagem, "moralização" (trabalhar para a felicidade). Em geral, corresponde à forma de trabalho industrial, tal como era concebida e praticada na época: a vigilância estrita do trabalhador na fábrica, o controle permanente pelo capataz, a impossibilidade de dispor de tempo livre durante o trabalho etc. (Zaffaroni \& Pierangeli, 2002, p. 279).
\end{abstract}

Outro elemento-chave de controle a serviço do sistema é a previsão legal de reavaliação da medida socioeducativa a cada 6 meses:

Art. 121. A internação constitui medida privativa da liberdade, sujeita aos princípios de brevidade, excepcionalidade e respeito à condição peculiar de pessoa em desenvolvimento.

$\S 1^{\circ}$ Será permitida a realização de atividades externas, a critério da equipe técnica 
da entidade, salvo expressa determinação judicial em contrário.

§ 2ำ A medida não comporta prazo determinado, devendo sua manutenção ser reavaliada, mediante decisão fundamentada, no máximo a cada seis meses.

§ $3^{\circ}$ Em nenhuma hipótese o período máximo de internação excederá a três anos. § 4ํㅡㄹ Atingido o limite estabelecido no parágrafo anterior, o adolescente deverá ser liberado, colocado em regime de semiliberdade ou de liberdade assistida.

§ 5 A liberação será compulsória aos vinte e um anos de idade.

§ 6ำ Em qualquer hipótese a desinternação será precedida de autorização judicial, ouvido o Ministério Público.

§ 70 A determinação judicial mencionada no § 1ำ poderá ser revista a qualquer tempo pela autoridade judiciária (Lei n. 8.069 [Estatuto da Criança e do Adolescente], 1990).

Sob um discurso positivo de necessária revisão do caso a qualquer tempo e no máximo a cada 6 meses, além da discricionariedade do Poder Judiciário, estamos diante de uma eficaz ferramenta a serviço do sistema punitivo e de controle instalado. Segundo Goffman (2008: pág, 208), "é característico mantê-los na ignorância das decisões que se tomam sobre o próprio destino". O desconhecimento do que se deve fazer e do tempo que resta para cumprir a medida socioeducativa produz preocupações e ansiedades, constituindo elementos subjetivos de controle do comportamento dos internos.

Outra questão relevante é que esses centros, em geral, têm muito poucos espaços (às vezes nenhum) de intimidade e tranquilidade, o adolescente não consegue ficar sozinho e carece de espaços fundamentais nessa etapa da vida, quando se deixa de ser criança para começa a se tornar um indivíduo adulto. Como reflete Goffman (2008: Pág, 209), "o interno quase nunca está completamente sozinho, sempre há alguém que pode vê-lo, ouvi-lo, mesmo que se trate de seus companheiros de internação".

Apesar da preocupação com terminologias e conceitos teóricos, as práticas são de segregação. Estamos diante de prisões para menores, rotuladas de "centros de socioeducação". Os adolescentes são organizados por módulos e fases, em função do comportamento, e em alguns estados, de acordo com a facção criminosa à qual pertencem. Em mais 10 anos de atuação junto a unidades de internação para adolescentes, não conheci nenhuma unidade que observasse a letra do Estatuto da Criança e do Adolescente (1990) e posteriormente do Sistema Nacional de Atendimento Socioeducativo (Sinase): "Art. 123. [...] obedecida rigorosa separação por critérios de idade, compleição física e gravidade da infração" (Conselho Nacional dos Direitos da Criança e do Adolescente [Conanda], 2006).

Toda instituição total pode representar-se como uma espécie de mar morto, lugar que emergem pequenas ilhas isoladas de arrebatadoras atividades. Tal atividade 
pode ajudar o indivíduo a suportar a tensão psicológica habitualmente provocada pelas agressões contra ele (Goffman, 2008, p. 125).

As unidades de privação de liberdade fazem parte do sistema de controle social, ou seja, todos esses trabalhadores do sistema socioeducativo estão a serviço do capital. Todos os profissionais que atuam nas medidas socioeducativas, no Poder Judiciário, no Ministério Público, na Defensoria Pública, na Polícia Militar (PM), são agentes a serviço desse sistema de controle social e suas tarefas giram em torno de manter a ordem social. $O$ denominador comum dos adolescentes privados de liberdade é que são jovens de classes menos favorecidas e todo o seu entorno tem baixo nível de influência positiva em sua vida.

Outro registro estarrecedor é o fato das unidades de atendimento socioeducativo serem locais recorrentes de óbito de adolescentes - os números são assustadores. Segundo o levantamento da Secretaria Especial dos Direitos Humanos (SDH, 2014), em 2012 foram a óbito 30 adolescentes no sistema socioeducativo brasileiro; já em 2013 morreram 29 adolescentes - média superior a 2 por mês. Como ilustra o Gráfico 1, as 3 principais causas de óbito em unidades de internação foram: conflito interpessoal (59\%); conflito generalizado (17\%); e suicídio (14\%).

Gráfico 1. Óbitos em Unidades de Internação para adolescentes no Brasil (2012-2013).

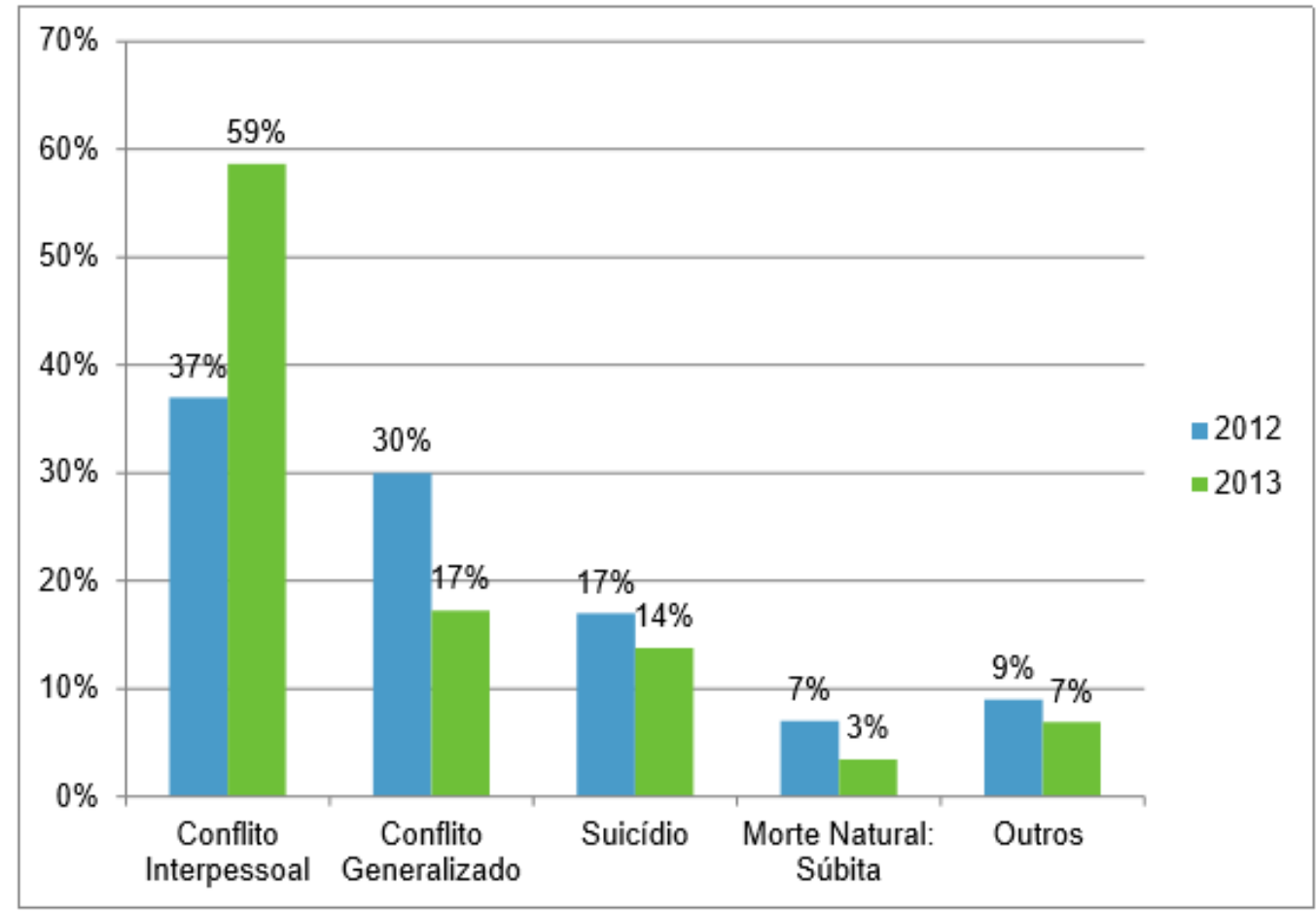

Fonte: Elaborado pelo autor. 
É para sociedade capitalista, não para os adolescentes, que serve o Sinase, configurando uma instituição destinada a manter a ordem, castigar quem nela se encontra (profissionais e adolescentes) e manter os usuários distantes da sociedade. Sempre que houver um conflito de interesses, os efeitos recairão sobre os adolescentes (p. ex., superlotação, internação como primeira medida socioeducativa, internação provisória como pena curta, entre outros).

Uma das funções desse sistema de controle social consiste em supervisionar as pessoas que apresentem características de "risco", supostamente para evitar danos e ajudar ("socioeducar") o adolescente. Trata-se do "panótipo", o "olho que tudo vê", que trata de examinar os comportamentos transgressores. Como aponta Foucault (1997), o verdadeiro fim desse exame de controle é outro: "normalizar" os indivíduos, evitar que criem perturbações e torná-los produtivos.

Nas unidades de privação de liberdade, os poucos cursos existentes, não disponíveis para todos, enfoca esse conceito de educação para o trabalho, mas com ofertas de qualificação para subempregos, que atendem aos interesses do capital. Nessa lógica, tentar convencer alguém a mudar seu comportamento pode sugerir educação, mas querer obrigar todos fazer as mesmas coisas acaba caracterizando um quadro de massificação, uma tirania terapêutica, que pode ser mais ou menos benevolente, paternalista e até assistencialista, mas seu fim é uma tirania.

Em alguma medida, a preocupação excessiva a respeito dos conceitos e efeitos que essas instituições têm sobre os jovens infratores pode ser interpretada como certa hipocrisia social, com emprego de termos como educação, reinserção social, socioeducação etc., buscando um caráter positivo dessa intervenção. Mas o certo é que nem sempre se faz aquilo que é dito, às vezes palavras elegantes, ideias rebuscadas, podem esconder práticas opostas ao discurso e ideário dessas unidades como instituições reguladoras de punição e violadoras de direitos.

Somente um trabalho reflexivo e teórico, com a pretensão de valorar e conhecer as práticas, permite tomar consciência do sentido dessas atividades. Propor ações, demonstrar limitações, acertos e erros ajuda a definir pontos de partida, referenciais para que possamos estabelecer uma coerência entre aquilo que se pretende e o que realmente ocorre nessas instituições de privação e liberdade de adolescentes.

\section{A intencionalidade oculta da privação de liberdade de adolescentes: o mito da socioeducação}

Com base na previsão do Sinase, evidencia-se a busca de atendimento ao adolescente em conflito com a lei, um processo de construção ou reconstrução de projetos de vida reais 
e potenciais que mudem suas rotas de vida, desatrelando-os da prática de atos infracionais. $O$ adolescente que adentra o mundo da criminalidade acredita ter encontrado alguma solução para os problemas que enfrenta, seja de ordem econômica, familiar, social e/ou emocional. Ajudá-lo a superar tal condição exige dos profissionais a implementação de uma proposta pedagógica que lhes dê todo o suporte para descobrir novas possibilidades de existência e encontrar novos caminhos para, gradativamente, resgatarem-se como seresno-mundo e seres-ao-mundo - como ideal, isso constituiria uma busca pela emancipação humana'. Assim, paulatinamente, os indivíduos poderão elaborar respostas adequadas aos seus problemas, sem entrar em conflito com a lei.

Basicamente, essa descrição é o que se almeja ao lidar com o termo socioeducação. Como define Costa (2006a, 2006b), socioeducar é educar para o convívio social e as unidades de atendimento deveriam construir uma metodologia de trabalho voltada a esse contexto. O Estatuto da Criança e do Adolescente (1990) dispõe que o cumprimento das medidas socioeducativas por parte dos adolescentes que praticam atos infracionais deve contemplar objetivos socioeducacionais, que devem garantir acesso às oportunidades que contribuam para sua participação autônoma na vida social. Desse modo, a garantia de um atendimento digno e humanizado ao adolescente que comete ato infracional ou ao qual se atribui o cometimento de tal ato é condição indispensável para que tal objetivo seja alcançado. Essa ação deve começar, necessariamente, já na apreensão do adolescente. Assim, devemos garantir uma política pública que tenha o objetivo de dar conta desse atendimento.

A socioeducação, como conceituada pelo pedagogo Costa (2006a, 2006b), deve ter como fundamento os princípios de liberdade e os ideais de solidariedade e, como fim, a formação plena do educando, sua preparação para o exercício da cidadania e sua qualificação para o trabalho. A ação socioeducativa, portanto, é a preparação do jovem para o convívio social; para isso concorrem todas as atividades para desenvolver seu potencial de ser e conviver, isto é, prepará-lo para conviver consigo mesmo e com os outros. Se essa meta não for alcançada, tudo terá sido inútil.

\footnotetext{
Ao se falar em medidas socioeducativas, está implícito que educar é possível mesmo àqueles que apresentam um comportamento divergente, mesmo sendo uma sanção, uma punição, pois restringe o ir e vir e determina a permanência em uma instituição socioeducativa. Contudo, essa sanção carrega princípios da socioeducação, ou seja, é por meio de mecanismos pedagógicos que se deve fazer a intervenção a favor do desenvolvimento tanto humano quanto social do adolescente (Fuchs, 2009, p. 171).
}

1 Em A questão judaica, Marx (2010, p. 103) expressou a concepção de que "a emancipação humana só será completa quando o indivíduo [...] tiver reconhecidos e organizados seus próprios poderes como poderes sociais, de tal modo que não mais separe dele próprio esse poder social como um poder político". 
Seguindo essa linha de raciocínio, percebemos que a socioeducação vai além da educação familiar e da educação escolar. Ultrapassa esses dois aspectos e bifurca-se em uma educação de caráter responsabilizador e protetivo de direitos, voltada ao trabalho social e educativo para jovens em conflito com a lei.

No viés prático, as ações pedagógicas devem adotar a educação interdimensional como concepção norteadora. Considerando a educação acadêmica, em suas formurlações mais avançadas, ela se baseia na integração das diversas disciplinas mediante conteúdos transversais - a "multi, inter e transdisciplinaridade". Já a proposta interdimensional, procura desenvolver o trabalho educativo com base nos 4 pilares da educação, com luz no saber da Grécia Antiga, que desenvolvia a pessoa humana nas dimensões do logos (razão), pathos (sentimento), eros (corporeidade) e mythos (espiritualidade).

Entretanto, o que está por trás desse atendimento, que traz em sua essência uma contradição entre a privação da liberdade de um jovem e sua formação, que tem, por um lado, uma resposta à sociedade, a busca pela formação social, pelo aprender a ser e a conviver, após se terem rompido regras e normas sociais? Como pensar a gestão de uma organização que tem como pressupostos prender e, ao mesmo tempo, formar um cidadão? Para fornecer outros elementos para a compreensão desse fenômeno, realizou-se uma reflexão a partir desta premissa: qual é a concepção do atendimento a adolescentes privados de liberdade "prender e formar" ou "prender para formatar?". Entende-se, aqui, formatar como punir. Mais do que buscar respostas para essa questão, o objetivo era compreender a finalidade do sistema, o permite discutir nas conclusões alguns aspectos relevantes para a gestão do atendimento socioeducativo de privação de liberdade, considerando sua complexidade e suas contradições. Essa pergunta norteadora foi adotada por se entender que há poucas discussões filosóficas, sociológicas, acerca da implementação do atendimento aos adolescentes infratores:

\footnotetext{
A implementação do atendimento aos adolescentes em conflito com a lei na maioria das vezes inviabiliza o acesso e a permanência ao sistema de garantia de direitos, e a materialização das políticas sociais públicas e da própria legislação. Isto é, sua operacionalização tem tido dificuldade para ser realizada em consonância com seu paradigma norteador. Essa crise é pior quando se trata da interpretação dos fundamentos críticos do [Estatuto da Criança e do Adolescente (ECA)], pouco aprofundado do ponto de vista filosófico, sociológico e jurídico, apesar de essa legislação já estar em vigor [há mais] de vinte anos (Oliveira e Silva, 2011, p. 99).
}

Enquanto ideal, trata-se de "prender e formar"; entretanto, o que se verifica na prática é o "prender para formatar". O trabalho socioeducativo realizado dentro das 
unidades carece de "revolução" dinâmica e permanente, não permitindo que o cotidiano, o dia a dia da unidade, venha a tornar o processo socieducativo uma rotina de produção em série, na qual o adolescente entra no sistema por determinação judicial e é tratado de forma igual a todos os outros que ali estão. Enquanto não houver a universalização do plano personalizado de atendimento (PPA), inclusive com propostas reais e adequadas para o projeto de vida do adolescente, infelizmente, as unidades terão maior similaridade com os centros de detenção. Dentro das unidades de atendimento são usados uniformes, cortes de cabelo e calçados padronizados, retirando de todos os adolescentes quaisquer possibilidades de destacar-se no grupo por sua identidade visual. Trata-se de um processo inconsciente de desconstrução da personalidade do indivíduo, com o objetivo de "formatar" um comportamento desejado dentro da instituição, mas que não se legitima para a vida do adolescente no momento em que "ganha" a liberdade. Nesse sentido, não são tratados quaisquer princípios que possam levar o adolescente à criação por si de uma consciência e espírito crítico. Em suma, tratam-se os efeitos, mas não a causa. Formata-se o indivíduo enquanto institucionalizado. Até o processo de escolarização dentro das unidades não se mostra adequado à realidade, tendo em vista que não considera a particularidade da medida socioeducativa, tratando todos igualmente. Nesse caso, não se segue o mais antigo dos princípios da justiça: tratar de modo igual os iguais e de modo desigual os desiguais.

A internação dos adolescentes, em sua maioria, visa a dar uma resposta à sociedade ou a uma medida protética, tendo pouca preocupação com a ressocialização deles, pois a maioria dos adolescentes internados era ignorada pelo Poder Público antes de sua internação e só foi lembrada em razão do ato infracional. Nessa perspectiva, o sistema socioeducativo é usado como mais uma ferramenta de dominação pelo Estado, uma última tentativa para forçar os adolescentes a se curvarem às regras da sociedade. Logo, por melhor que seja uma unidade socioeducativa, via de regra seu trabalho é perdido, pois, tão logo o adolescente volte para o meio de onde veio, ele volta a ser esquecido se não cometer outro ato infracional.

\footnotetext{
Se a finalidade da sanção não é somente a punição, essa deve ser exercida nos princípios da educação, por isso a medida é denominada socioeducativa. Não há dúvidas entre os operadores da justiça de que a medida socioeducativa tem como função o controle social das práticas infracionais. Contudo, a finalidade pedagógica demarcada na norma legal é compreendida e interpretada de diferentes maneiras pelos executores da medida, traduzindo-se muitas vezes em práticas institucionais que caminham no sentido contrário ao que efetivamente significa o caráter pedagógico da medida socioeducativa (Fuchs, 2009, p. 183).
} 
Uma vez que o Estado se responsabilize pela tutela do adolescente, enquanto este estiver cumprindo medida socioeducativa, seus direitos básicos preconizados pela Constituição da República Federativa do Brasil (CF, 1988) e pelo Estatuto da Criança e do Adolescente (1990) deverão ser garantidos. Antes de "prender", o que se questiona é se esse Estado não poderia proporcionar melhores condições, dignas, à família e aos próprios adolescentes, visando ao acesso aos bens sociais e à garantia de inclusão igualitária aos demais cidadãos para sua ascensão social. Infelizmente, muitas vezes o acesso às condições materiais indispensáveis para o desenvolvimento físico-psico-social desses adolescentes vem junto com sua entrada nas instituições de privação ou restrição de liberdade.

[...] com o ECA, engendrou-se uma nova mecânica de controle social, que não é tão somente dirigido aos pobres. É controle sociopenal formalmente instituído com fundamentos no direito penal juvenil, permanente e continuamente definido pelos fluxos inteligentes e pela ética da sociedade da transparência, num Estado Democrático de Direitos. Esses fluxos de controle, sejam penais ou não, continuam controlando os potencialmente perigosos, com base no paradigma da defesa da sociedade, que é um princípio do direito penal (Oliveira e Silva, 2011, p. 227).

A privação de liberdade é uma punição, parte da retribuição imposta pelo Estado. Prende-se para punir. A tentativa de agregar valores morais ao castigo é uma forma de mitigar a aflição da medida. A nomenclatura "medida socioeducativa de internação em estabelecimento educacional" segue no mesmo sentido. Trata-se de um eufemismo. Historicamente, socioeducar está para a internação assim como ressocializar está para a pena. Por melhor que seja o programa, essa realidade não pode ser ignorada. Todavia, ainda não encontramos outra forma de impor limites às pessoas que desrespeitam direitos alheios. E provavelmente não encontraremos outra forma, exceto se deixarmos de lado direitos e garantias fundamentais, ética e valores morais, e aceitarmos o emprego das tecnologias de segurança para o controle corporal dessas pessoas.

A grande questão é por que estes adolescentes seguiram este caminho? Por que se encontram em uma unidade socioeducativa? Parte deles não tiveram oportunidades durante toda sua vida e o fato de estarem em uma unidade deve ser visto com uma possibilidade de aprendizado, de conhecimento, para saírem com oportunidades reais para a construção de um novo projeto de vida. Assim, a concepção correta seria a privação de liberdade como um processo formativo, pois as unidades seriam locais para subsidiar processos de escolhas aos adolescentes. A vida de todos se baseia em experiências e vivências e só assim podemos fazer algo que realmente transforme esses adolescentes, ou seja, escolher seu caminho, fazer suas escolhas, tomar suas decisões. Prender para formatar, para a punição, 
é um conceito errôneo, pois o fato de estar sem liberdade não significa uma mudança automática na vida do adolescente ou de qualquer pessoa.

Diante desse registro, que evidencia o breve ciclo de perversidades, violações e arbitrariedades, permanece a velha figura do "infrator adolescente" subordinado a um Sistema de Administração da Justiça Juvenil que gerencia vidas, naturalizando a questão social como penal, na ordem capitalista. É um sistema que, ao invés de promover justiça, promove injustiça, e arbitrariedades institucionais cuja existência tem a idade do Brasil (Oliveira e Silva, 2011, p. 220).

A concepção de atendimento aos adolescentes deve estar alicerçada na construção de uma sociedade que garanta direitos, conduzindo a proposta de permitir o desenvolvimento do indivíduo de maneira obrigatória, em relação a si e à sociedade. A proposição de prender e formar exige uma reflexão e interação contínua dos envolvidos no processo, pois a necessidade de responder à sociedade, a tendência a minorar as dificuldades, levanos a prender para formatar, exigir que o adolescente se adapte a "normas e preceitos" institucionais. A expectativa seria uma penalização, responsável, com projeto políticopedagógico, a busca pela autonomia desse sujeito, pois não é possível pensar em um processo formativo/educativo sem responsabilização e, muitas vezes, para chamar o adolescente a refletir sobre sua responsabilidade é necessário que ele seja temporariamente privado de sua liberdade, recebendo atendimento para assumir uma nova forma de pensar e agir.

Uma vez que seja determinada a privação de liberdade de um adolescente, faz-se necessário proporcionar condições ao processo formativo, tendo por objeto 0 desenvolvimento do sujeito e a carência/os prejuízos no processo formativo anterior à privação de liberdade e o envolvimento em atos infracionais. No entanto, deve-se estabelecer o trabalho conjunto de promoção da família ou dos responsáveis que receberão o adolescente após o processo socioeducativo.

Infelizmente, a socioeducação, assim como todo o sistema de ensino brasileiro, está adaptando o indivíduo ao meio, falta muito para construirmos um processo educativo emancipador. Há duas perspectivas a discutir: "prender e formar" refere-se ao ideal da proposta socioeducativa para formar sujeitos para a vida em sociedade, mas o questionamento a fazer é: formar para qual sociedade? Então, o que ocorre é punir como resposta a anseios da sociedade. Nesse aspecto, colocamo-nos diante da realidade que perpassa o atendimento socioeducativo e representa a perspectiva "prender para formatar", já que há uma aparente necessidade de tornar esse adolescente "apto" a conviver em sociedade. Prender e formar: eis o caminho, considerando sua individualidade e contando com seu protagonismo como condutor de uma nova história. Mas o sistema tenta privar por privar, é a prisão no sentido da palavra. Formatar é tirar da pessoa seu protagonismo e sua individualidade, moldá-la conforme a percepção alheia e não a sua. 
A concepção formadora seria a melhor proposta, considerando a concepção sociopedagógica, as práticas socioeducativas, a dinâmica funcional almejada, o modelo arquitetônico previsto, as legislações infanto-juvenis sancionadas e, finalmente, o adolescente enquanto sujeito de direitos e respeitada sua singularidade, aproveitando seu passado para repensar o presente e projetar um futuro, contribuindo com a formação desse cidadão, devolvendo-Ihe sua dignidade e mostrando-Ihe os caminhos que não aqueles trilhados até o momento.

Tal qual a escola, que em uma sociedade desigual representa a igualdade, ou no termo jurídico que mais representa o liberalismo, a isonomia, os adolescentes são colocados como iguais, promovendo meios de formatá-los ao tipo esperado pela sociedade da competição, diante desses meios os adolescentes correspondem da seguinte forma: uns menos, uns mais, outros mais ou menos. Legitimamos, dessa forma, tal qual uma escola, a existência daqueles jovens nota 10, daquela nota média, daqueles abaixo da média, estes mais próximos de ficarem abaixo da terra também.

Em um plano formal e normativo, a apreensão do adolescente deve conjugar e atender ao caráter sancionatório e formativo e um discurso favorável à garantia de direitos. Todavia, existe um objetivo, que é velado, de prendê-los para a garantia da paz social. Nesse sentido, as previsões legais são diferentes das práticas, não existem reais interesses, investimentos e recursos disponíveis para atingir os objetivos estabelecidos para as medidas socioeducativas, que aprisionam para segregar. Isso nos faz refletir sobre o modus operandi do trabalho socioeducativo. As normativas nacionais e internacionais, enquanto poder de privar um jovem de liberdade nos termos da lei, balizam e orientam a forma como se deve direcionar o atendimento socioeducativo. O objetivo geral do trabalho é desenvolver um processo capaz de suscitar um novo projeto de vida para os adolescentes, baseado em valores éticos e na participação social cidadã, daí, também, a necessidade de formação dos profissionais e da construção coletiva para a definição dos métodos de trabalho. A chave de compreensão dessa premissa é o tipo de trabalho que os gestores adotarão para conduzir a relação educador-educando. Os parâmetros arquitetônicos contribuem, os recursos humanos conduzem, a estrutura e os materiais apoiam, todavia, os métodos direcionam e mostram o caminho por meio de princípios e diretrizes. As instituições não podem querer dar novos rumos à vida desses jovens, pois não podemos retirar a essência dos adolescentes, mas as instituições podem fornecer instrumentos e técnicas que subsidiem suas escolhas.

A cultura que prevalece nas instituições de privação de liberdade favorece a "formatação", a repressão, a punição e a "gratificação" segundo uma lógica de "merecimento" e ao fechamento em si. Tal tendência não é exclusiva dos centros socioeducativos e apresenta importantes fatores históricos relativos à institucionalização de crianças e adolescentes e ao aprisionamento de pessoas em geral. Entendemos que a 
efetivação da socioeducação nos ambientes de privação de liberdade vai na contramão desse processo, exigindo, mais do que uma proposta consistente, uma prática pautada em esforços diários. O cotidiano ${ }^{2}$ na unidade de internação possibilita identificar que as práticas profissionais na instituição são alvo de demandas das mais diversas ordens: normativas, restritivas, sancionatórias, protetivas, psicológicas, psiquiátricas, de vigilância, de segurança, de reclusão, de exibição midiática, da moral, da saúde do corpo e da mente, da disciplina, da família... e esta lista segue sem fim. Diante de tal situação, a atuação dos profissionais da instituição socioeducativa, não raro, se depara com a exigência de "respostas" rápidas, seguras e eficazes, correndo o risco de perder a direção e tornar-se inconsistente, ou ser levada pelas tendências mencionadas. Conhecer os fundamentos da proposta de atendimento aos adolescentes e colocar periodicamente a prática em questão, promovendo seu aprimoramento, pode levar-nos a reconhecer, no ambiente institucional, oportunidades formadoras e não meramente formatadoras, punitivas.

\section{Referências bibliográficas}

Bourdieu, P. (1989). O poder simbólico. Lisboa, Portugal: Difel.

Conselho Nacional dos Direitos da Criança e do Adolescente. (2006). Sistema Nacional de Atendimento Socioeducativo - SINASE. Brasília, DF: Conanda.

Constituição da República Federativa do Brasil, de 5 de outubro de 1988. (1988). Brasília, DF.

Costa, A. C. G. (2006a). As bases éticas da ação socioeducativa: referenciais normativos e princípios norteadores. Brasília, DF: Secretaria Especial dos Direitos Humanos.

Costa, A. C. G. (2006b). Os regimes de atendimento no estatuto da criança e do adolescente: perspectivas e desafios. Brasília, DF: Secretaria Especial dos Direitos Humanos.

Foucault, M. (1997). Vigiar e punir: nascimento da prisão. Petrópolis, RJ: Vozes.

Fuchs, A. M. S. (2009). Telhado de vidro: as intermitências do atendimento socioeducativo de adolescentes em semiliberdade. Análise nacional no período de 2004-2008 (Tese de Doutorado). Universidade de Brasília, Brasília, DF.

Goffman, E. (2008). Manicômios, prisões e conventos (7a ed.). São Paulo, SP: Perspectiva.

HELLER, Agnes. O cotidiano e a história. Trad. Carlos Nelson Coutinho e Leandro Konder. São Paulo: Paz e Terra, 2000

Lei n. 8.069, de 13 de julho de 1990. (1990). Dispõe sobre o Estatuto da Criança e do Adolescente e dá outras providências. Brasília, DF.

2 Em O cotidiano e a história, Agnes Heller (2000, p. 20) define: "a vida cotidiana não está 'fora da história', mas no 'centro' do acontecer histórico: é a verdadeira 'essência' da substância social [...] A vida cotidiana é a vida do indivíduo. O indivíduo é sempre, simultaneamente, ser particular e ser genérico". 
MARX, Karl. Sobre a questão judaica. Boitempo Editorial: São Paulo, 2010.

Oliveira e Silva, M. L. (2011). Entre proteção e punição: o controle sociopenal dos adolescentes. São Paulo, SP: Ed. Unifesp.

Secretaria Especial dos Direitos Humanos. (2014). Levantamento Nacional do Sistema de Atendimento Socioeducativo - SINASE. Brasília, DF: SDH.

Zaffaroni, E. R., \& Pierangeli, J. H. (2002). Manual de direito penal brasileiro: parte geral (4a ed.). São Paulo, SP: Revista dos Tribunais.

\section{Para citar este artigo}

\section{Norma A - ABNT}

PEIXOTO, R. B. Sistema Nacional de Atendimento Socioeducativo como mecanismo de regulamentação da punição. Conhecer: Debate entre o Público e o Privado, v. 11, n. 27, p. 134-149, 2021.

\section{Norma B - APA}

Peixoto, R. B. (2021). Sistema Nacional de Atendimento Socioeducativo como mecanismo de regulamentação da punição. Conhecer: Debate entre o Público e o Privado, 11(27), 134-149.

\section{Norma C - Vancouver}

Peixoto RB. Sistema Nacional de Atendimento Socioeducativo como mecanismo de regulamentação da punição. Conhecer: Debate entre o Público e o Privado [Internet]. 2021 [cited Ago 21, 2021];11(27):134-149.

Available from: https://revistas.uece.br/index.php/revistaconhecer/article/view/7155 